Voix et Images

voixetimages

\title{
France Théoret : narratrice de la subjectivité
}

Présentation

\section{Patricia Smart}

Volume 14, numéro 1 (39), automne 1988

France Théoret : narratrice de la subjectivité

URI : https://id.erudit.org/iderudit/200746ar

DOI : https://doi.org/10.7202/200746ar

Aller au sommaire du numéro

Éditeur(s)

Université du Québec à Montréal

ISSN

0318-9201 (imprimé)

1705-933X (numérique)

Découvrir la revue

Citer ce document

Smart, P. (1988). France Théoret : narratrice de la subjectivité : présentation.

Voix et Images, 14(1), 6-7. https://doi.org/10.7202/200746ar d'utilisation que vous pouvez consulter en ligne.

https://apropos.erudit.org/fr/usagers/politique-dutilisation/ 


\title{
France Théoret: narratrice de la subjectivité. Présentation
}

\author{
par Patricia Smart, université Carleton, Ottawa
}

Le défi de toute écriture qui se veut engagée est peut-être de trouver le rythme et la sonorité d'une voix où se rencontrent les accents de l'individuel et du collectif, une structure narrative où le cheminement du «je» vers le sens de son propre périple dans le temps historique s'articule sur l'expérience d'un peuple, ou d'une classe, ou d'un groupe social. Vue selon l'angle de vision raréfié de notre hyperconsciente fin de siècle, l'époque de la Révolution tranquille - où l'existence d'un état de "syntonie» entre les écrivains et le peuple québécois semblait aller de soi - éveille un souvenir nostalgique, envieux même. Mais il est clair que ni la conjoncture politique actuelle ni notre connaissance des modes de fonctionnement du discours ne permettent plus à l'écrivaine une projection aussi instinctive de sa propre quête d'identité sur celle de la collectivité. Pour France Théoret, écrivant à l'époque de la modernité et de la post-modernité, il s'agit d'un lien beaucoup plus ténu entre l'individuel et le collectif - un tenace désir d'ouverture à l'autre qui amène l'écrivaine, traversée comme elle est par les voix des aïeules, des proches, des conscurs et des concitoyens, à faire de ce thêâtre des voix une esthétique et une recherche de sens vital. Projet de construction de sens qui à chaque pas, pour ne pas reproduire les dogmatismes qui annulent la différence, déconstruit toute certitude qui ne résiste pas à l'épreuve de cette écoute de l'autre. Ce faisant, Théoret se fait la «narratrice de la subjectivité» et des subjectivités, l'ambition théorique et la fidélité au réel étant toujours étroitement liées dans ses écrits.

Chacun des articles qui suivent interroge le caractère intensément privé et pourtant public - politique - de cette écriture où, comme le remarque Louise Dupré, le mot femme est le fil d'Ariane organisant tous les sens du texte. Mot qui dès le début de la démarche poétique, selon Dupré, amène l'auteure à se distancier des formalismes à la mode et à élaborer un enchevêtrement formel d'autobiographie, de fiction et de théorie - dialectique sans fin où rien n'est jamais acquis, si ce n'est la diffraction du moi qui assume l'ouverture comme la condition essentielle de son authenticité. Dans son étude de Nécessairement putain, Karen Gould pousse plus loin l'écoute du «concert des voix» qui anime l'écriture de Théoret en analysant la structure de domination présente dans le discours et dans le réel qui permet à l'auteure de faire de la putain le signe et le symbole de toutes les femmes, enfermées dans leur corps et dans le mutisme par une société dont la course au profit n'est qu'une des modalités de son acquiescement devant le regard censurant du Père. C'est du regard du lecteur qu'il est question dans le texte de Claudine Potvin, qui a trouvé dans le détail - flashes, «banalités du quotidien», sons et images de l'ordinaire dans toute son 
insignifiance - le principe de composition de Nous parlerons comme on écrit. Signes du privé étalé au grand jour, les détails éloignent le texte de toute esthétique «classique», interpellant le regard du lecteur d'une façon inattendue et amenant le roman vers le statut d'une écoute. Enfin Claire Lejeune, dans un dialogue aussi personnel que philosophique avec l'auteure d'Entre raison et déraison, situe la pensée de Théoret dans le processus de déconstruction du langage et de la réalité patriarcale entrepris par le féminisme de nos jours, et dévoile l'énormité des conséquences qu'elle met en branle dans l'Histoire. Car dans la rigueur de cette pensée qui refuse pourtant de faire taire les voix de la «turbulence intérieure», c'est la parole féminine gelée depuis la nuit des temps dans les sous-sols de la raison geôlière qui refait surface et qui, ce faisant, déstabilise irréversiblement les structures de l'empire patriarcal.

On remarquera peut-être le fait qu'aucun homme n'a répondu à la demande de contributions que nous avons faite en préparant ce dossier. Question de temps? Priorités autres que l'étude d'une auteure féministe? Ou tout simplement désir d'écouter pour une fois, et de donner la place entière aux femmes dans les pages de Voix \& images? On regrette leur absence tout de même... et cela aussi est peut-être un signe des temps.

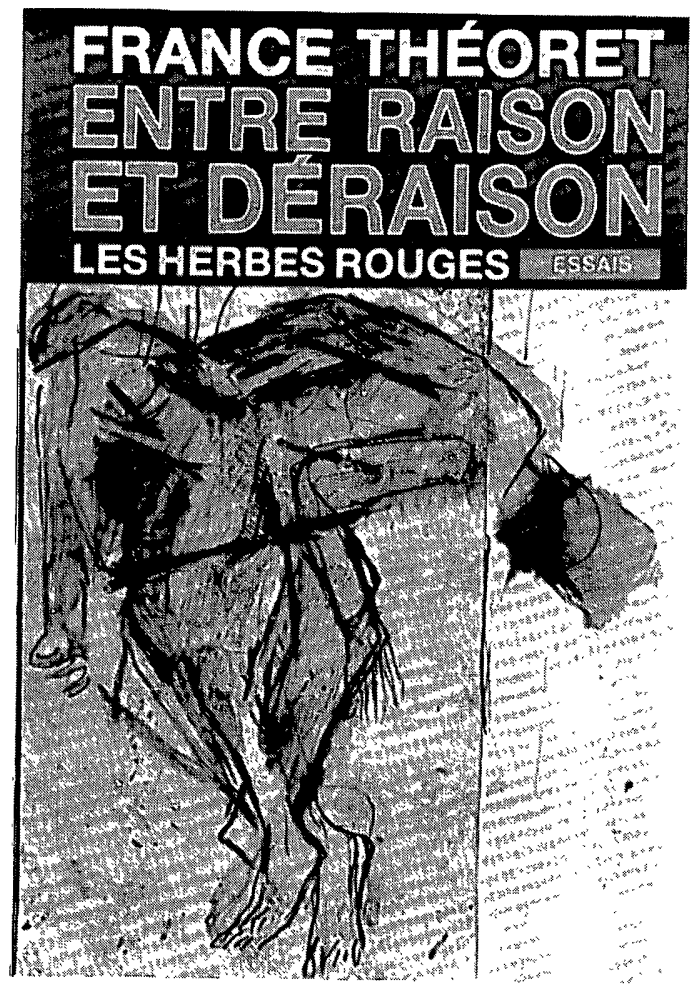

